\title{
Design, Construction and Testing of JP Mini Radio Broadcast Transmitter and Audio Console
}

\author{
JP.C. Mbagwu ${ }^{1 *}$,U.C. Ozuomba ${ }^{2}$, Z.L. Abubakar ${ }^{3}$, J.O. Ozuomba ${ }^{1}$ \\ ${ }^{I}$ Department of Physics, Imo State University, Owerri, Nigeria. \\ ${ }^{2}$ Department of Architecture, Faculty of Environmental Sciences, CaritasUniversity, Enugu, Nigeria. \\ ${ }^{3} 32$ Artillery Brigade Owena Cantonment Akure, Ondo, Nigeria.
}

*Corresponding Author: JP.C. Mbagwu, Department of Physics, Imo State University, Owerri, Nigeria.

\begin{abstract}
The early transmitter for radio broadcasting is so big and bulky that they do occupy numerous spaces. The circuits are mainly designed with valves, which are big in sizes. With the advent of semiconductor materials such as transistors, electronic equipment is now becoming miniaturized such that small transmitters are now handy and compact. In line with this, we choose to design a complete radio broadcasting equipment that is compact. The system units are of two categories, namely: audio console for the processing and mixing of musicals which is basically a condenser microphone. The transmitter unit is where the center frequency is provided. All these were designed to be in compact form. This project is aimed at serving a community using a small radio broadcasting equipment with a power rating of 20 watts. A community of 100 meters in radius should be covered comfortably. The study was to design and construct a power rating of 20-watt Frequency Modulation (FM) transmitter to be received at a range of 100 meters. The transmitter has an audio jack port which picks up very weak sound signals, a transistor, resistors, inductor, and capacitors. The design procedure involves the modification of an output of the transmitter. Based on the procedures adopted, and the tests carried out, the specific findings include a range of $98.5 \mathrm{MHz}$ of transmission from a $9 \mathrm{~V} \mathrm{DC}$ battery. The work indicated that the practical frequency modulated (FM) transmitter requiring a low power of 20 Watt can be designed and constructed effectively.
\end{abstract}

Keywords: Radio Broadcast, FM Transmitter, Frequency Modulation, Antenna and Audio Console.

\section{INTRODUCTION}

An FM transmitter can either be built into a device or be a portable appliance that plugs into the headphone jack or proprietary output port of a portable audio or video device, such as a portable media player, CD player, or satellite radio system. The sound is then broadcast through the transmitter, and plays through an FM broadcast band frequency. Purposes for an FM transmitter include playing music from a device through a car stereo, or any radio. The FM transmitter plugs into the audio output of audio devices and converts the audio output into an FM radio signal, which can then be picked up by appliances such as car or portable radios. Most devices on the market typically have a short range of up to 100 feet (30 meters) with any average radio (up to about 300 feet (100 meters) with a very good radio under perfect conditions) this range can also be enhanced if operated in fixed locations of good high elevation, such as a multi-story apartment or tall building and can broadcast on any FM frequency from 87.5 to $108.0 \mathrm{MHz}$ in most of the world, (or 88.1 to 107.9 in the US and Canada). Some lower-cost transmitters are hard-wired to the 87.7-91.9 MHz band allocated to educationalbroadcasts in the United States, or a certain other smaller range of frequencies. A transmitter is an electronic device, which, with the aid of an antenna, propagates an electromagnetic signal such as radio, television or other telecommunication signals(Ogbuanya et al., 2017). Of all three types of modulation, frequency modulation is the most suitable for the type of broadcasting required for this project due to its not too complicated circuitry and other advantages like resilience to noise, resilience to signal strength variations. Radio is the use of electromagnetic waves to carry information such as sound by systematically modulating some property of electromagnetic energy waves transmitted through space such as amplitude, frequency, phase or pulse width (Farlex, 2014). 


\section{MATERIALS AND METHODS}

\subsection{Materials}

Transistor: (2N3904)

Resistors: $10 \mathrm{k} \mathrm{ohm}, 27 \mathrm{k} \mathrm{ohm}, 470 \mathrm{ohm}$

Audio jack port

Capacitors: $22 \mu f, 0.01 \mu f(103), 10 p f$.

9 Volts Power supply DC Battery, Bread board, Copper clad board (CCB), Soldering Iron, Soldering lead, F.M radio receiver, Multi-meter and Jumper Wires.

\section{i. Audio Jack Port}

Audio jack port is a transducer, which converts sound energy to electric energy. It consists of parallel plate capacitor which has one plate as fixed and other plate being movable. The movable plate is called diaphragm. When sound strikes diaphragm it starts moving, thus in turn changing capacitance of capacitor, which in turn results in flow of variable current.

\section{ii. Transistor (2N3904)}

Transistor 2N3904 is a medium gain general-purpose transistor. It is widely used for low power amplification. It has transition frequency of around $300 \mathrm{MHz}$ with a minimum current gain of 100Ampere.

\subsection{Methods}

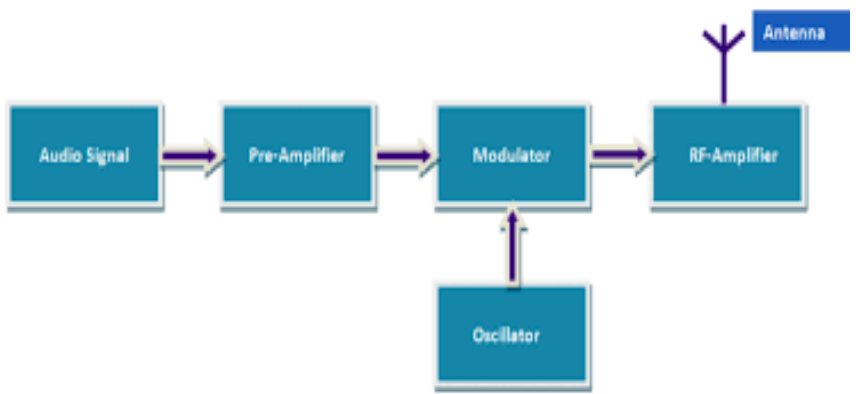

Figure1. Block Diagram of FM Transmitter

Each Of These Sections Is Explained Below:

\section{Audio Signal}

An audio signal is a representation of sound, typically using a level of electrical voltage for analog signals, and a series of binary numbers for digital signals. Audio signals have frequencies in the audio frequency range of roughly 20 to $20,000 \mathrm{~Hz}$, which corresponds to the lower and upper limits of human hearing.

\section{Pre-amplifier}

Is an electronic amplifier that converts a weak electrical signal into an output signal strong enough to be noise-tolerant and strong enough for further processing, or for sending to a power amplifier and a loudspeaker. Without this, the final signal would be noisy or distorted.

\section{Modulator}

A modulator is a device that performs modulation. A demodulator (sometimes detector or demod) is a device that performs demodulation, the inverse of modulation. A modem (from modulatordemodulator) can perform both operations.

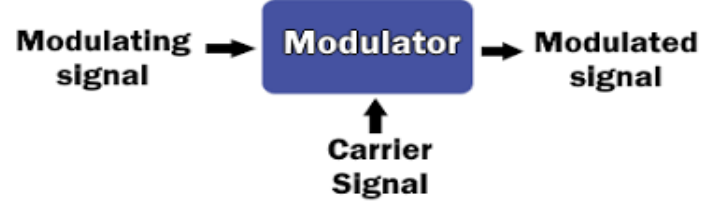

Figure2. Block Diagram of a Modulator 


\section{Oscillator}

An oscillator is a circuit which produces a continuous, repeated, alternating waveform without any input. Oscillators basically convert unidirectional current flow from a DC source into an alternating waveform which is of the desired frequency, as decided by its circuit components.

\section{RF-Amplifier}

A radio frequency power amplifier (RF power amplifier) is a type of electronic amplifier that converts a low-power radio-frequency signal into a higher power signal typically, RF power amplifiers drive the antenna of a transmitter.

\section{Antenna}

An antenna is the interface between radio waves propagating through space and electric currents moving in metal conductors, used with a transmitter or receiver. An antenna is an array of conductors (elements), electrically connected to the receiver or transmitter.

\subsection{Construction and Materials Used}

The materials used in testing the circuit are:

i. Project Board:This is a white electronic kit, which is used to test and construct electronic circuit without soldering the components. It provides room for circuit modification if need be.

ii. Connecting Wires:These are tiny pieces of copper wires about $0.2 \mathrm{~mm}^{2}$ in diameter. They are used to assemble components together on the project board.

iii. Battery:The source dc supply is 9volts high watt battery.

iv. Cutter:This is to cut connecting wires and components to size.

v. Digital Multi-meter:This is a multipurpose electrical measuring instrument use to test for various parameters in an electrical circuit.

\section{vi. Insulation Tape \\ vii. Complete Pliers Set \\ viii. Screw driver}

\subsection{Design Procedure}

The design procedure for the project hinged on an existing frequency modulated (FM) transmitter circuit. This transmitter circuit, which the researchers constructed and tested, exhibited some desirable characteristics that qualified it as a base for further design. Operating efficiently on a low-power 9 V DC (Direct Current) which produces minimal safety problem, the transmitter produced sound output with optimum signal-noise ratio (SNR) and high fidelity comparable to practice broadcast transmitter.

However, the transmitter incorporates a low power $(20 w)$ output stage using a general purpose (NPN) transistor $2 N 3904$ which produces a range too short for practical application. The design procedure then involved the calculations experiments and exercises required to successfully replace the low output of the existing transmitter with less output stage of useful broadcast value.

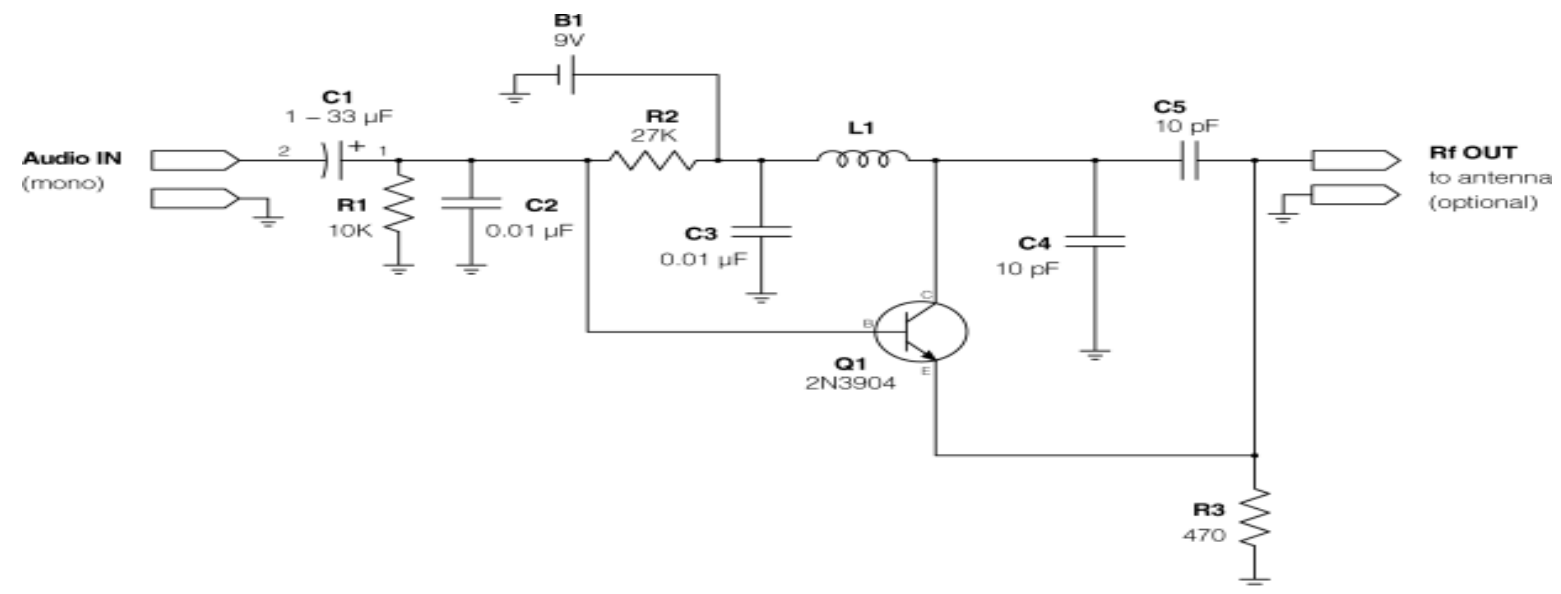

Figure3. Overall Circuit Diagram 


\subsection{Design Construction}

The actual realization of the design was carried out in adherence to circuit schematics. Assembled first on bread board before transferring to a Copper Clad board (CCB). The choice of electronic materials and components used were done with the objective of achieving low power rating of 20 watts.

\subsection{Design Calculation}

\section{i. Transmitter Distance (d)}

From the Global Positioning System (GPS), using the fields Area measurement software, a total population distance of the transmission of $35777 \mathrm{~km}=35.777 \times 10^{3} \mathrm{~m}$ was obtained as the total range to be covered by the transmitter.

\section{ii The population distance of the transmissiond ${ }_{p t}$}

Using the formula $\mathrm{d}_{p t}=\sqrt{2 h R}$

Where:

$\mathrm{d}_{p t}=$ be the population distance of the transmission.

$\mathrm{h}=$ height of tower (100 meters)

$\mathrm{R}=6400 \mathrm{~km}=6.4 \times 10^{6} \mathrm{~m}$

$\mathrm{R}=$ Radius of the earth

Population density $\left(\mathrm{P}_{d}\right)=500$ per square kilometer.

$\mathrm{d}_{\mathrm{pt}}=\sqrt{2 \times 100 \times 6.4 \times 10^{6}}$

$\mathrm{d}_{p t}=35777 \mathrm{~km}$

$\therefore \mathrm{d}_{p t}=35.77 \times 10^{3} \mathrm{~m}$

Area reach $\left(\mathrm{A}_{r}\right)=\pi \mathrm{d}_{p t}^{2}$

$\pi=3.142$

$\mathrm{d}_{p t}=35.77 \times 10^{3} \mathrm{~m}$

$\mathrm{A}_{r}=3.142 \times(35.77)^{2}$

$\therefore \mathrm{A}_{r}=4020$ square kilometer

Let population reach be $\mathrm{P}_{r}$, Area reach be $\mathrm{A}_{r}$ andPopulation density be $\mathrm{P}_{d}$.

$\mathrm{P}_{r}=\mathrm{A}_{r} \times \mathrm{P}_{d}$

$\mathrm{A}_{r}=4020$ square kilometer,

$\mathrm{P}_{d}=500$ per square kilometer

$\mathrm{P}_{r}=4020 \times 500$

$\mathrm{P}_{r}=2010000$

$\therefore \mathrm{P}_{r}=2.01 \times 10^{6}$ or 2.01 million

$\therefore$ Coverage range $\left(C_{r}\right)=35.777$

Population reach $\left(\mathrm{P}_{r}\right)=2.01$ million

\section{iii. Free Space Path Loss (FSPL)}

In telecommunication, the free space path loss (FSPL) is the attenuation of radio energy between the feed points of two antennas that results from the combination of the receiving antenna's capture area plus the obstacle free, line of sight path through free space (usually air).

The equation for FSPL is 
$F S P L=\left(\frac{4 \pi \mathrm{d}_{p t}}{\lambda}\right)^{2}$

But $\lambda=\frac{C}{f}$

$F S P L=20 \log \left(\frac{4 \pi \mathrm{d}_{p t} f}{C}\right)^{2}$

Where:

FSPL $=$ free space path loss

$\lambda=$ the signal wavelength (in meters)

$f=$ signal frequency (in hertz)

$\mathrm{d}_{p t}=$ distance between transmit and receive antennas (in meters)

$\mathrm{c}=$ The speed of light in a vacuum, $2.99 \times 10^{8}$ meters per second.

$\mathrm{d}_{p t}=35777000 \mathrm{~m}, \mathrm{f}=98.5 \mathrm{MHz}=98.5 \times 10^{6} \mathrm{~Hz}, c=2.99 \times 10^{8} \mathrm{~m} / \mathrm{s}$

$F S P L=20 \log \left(\frac{4 \times \pi \times 35777000 \times 98.5 \times 10^{6}}{2.99 \times 10^{8}}\right)$

$F S P L=20 \log \left(\frac{4.42 \times 10^{16}}{2.99 \times 10^{8}}\right)$

$F S P L=20 \log (147826087)$

$\therefore F S P L=163 \mathrm{~dB}$

In $35777 \mathrm{~km}$ the free space path loss is about 163 Decibels.

\section{Overview of the free space path loss}

When a radio signal travels from the transmit antenna to the receive antenna, it will suffer a loss of strength due to its spreading. The farther the distance between the transmit and receive antenna, the wider the "spread" of the signal and the greater the free space path loss (FSPL)

\section{iv. The Sensitivity of Radio Receiver}

Table1. Sensitivity of radio receiver

\begin{tabular}{|l|c|}
\hline Name & Sensitivity \\
\hline $\begin{array}{l}\text { KCHIBO FM/MW/SW 1-18 } \\
\text { 20 Band Receiver }\end{array}$ & $20 \mu V / m$ \\
\hline
\end{tabular}

If a radio receiver is quoted as having a sensitivity of $20 \mu \mathrm{V} / \mathrm{m}$ then this is the weakest signal that the particular receiver can "hear". To receive signals or stations weaker than this, then a high gain antenna or preamplifier is required. The problem with amplifying weak signals, is that you also amplify the inherent background noise that is present.

For example, JP FM $98.5 \mathrm{MHz}$ broadcasts a signal with a 20Watts transmitter then what is the field strength at a distance of 100 meters.

Using $E_{f s}=\frac{\sqrt{30 P_{t}}}{d}$

Where:

$E_{f_{s}}=$ is the field strength in $\mathrm{v} / \mathrm{m}$

$d_{t}=$ is the distance covered by the transmitter in meters.

$P_{t}=$ transmitter power in watts

$P_{t}=20 \mathrm{watt}$ and $d_{t}=100$ meters

$E=\frac{\sqrt{30 \times 20}}{100}$ 
$E=\frac{\sqrt{600}}{100}$

$\therefore E=0.244 \mathrm{v} / \mathrm{m}$

$\therefore 0.244 \mathrm{v} / \mathrm{m}$ is the field strength in thetransmitter.

It should be noted that equation (1) assumes $100 \%$ energy is transferred from the transmitter to the antenna, and that the antenna has unity gain (a dipole). In practice, there are losses in coupling the signal from transmitter to antenna, and also losses in the antenna itself. The formula in equation (1) assumes that all energy leaving the transmitter is converted to Radio Frequency (RF) energy, there are no losses in the transmitting or receiving antenna and no loss in the path from transmitter (TX) to receiver (RX). In all cases these conditions are never met. There are losses in the receiving and transmitting antenna, and the signal is attenuated on its way to the receiver (RX). Tress, buildings, hills all reduce radio waves before they reach the receiver.

\section{v. Near and Far Field}

Antenna characteristics differ with design and operating frequency and many factors that affect performance. All transmitting antennas have regions called the near and far field. These regions are shown in figure 4 below.

The center vertical line represents the length of the antenna, $L$, in meters. $\mathrm{R}$ represents the radius of the near field.

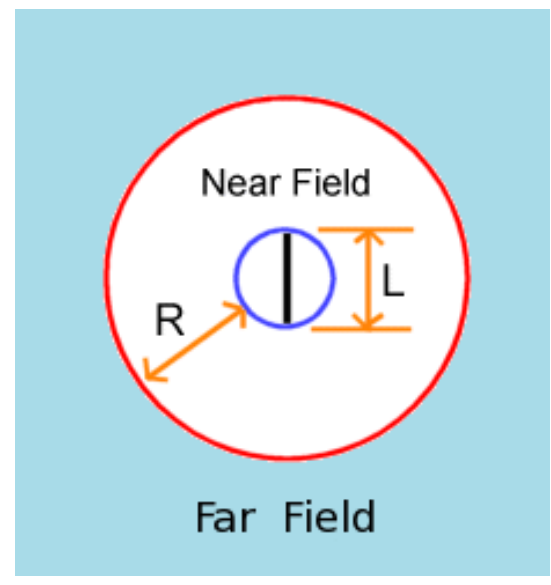

Figure4. Near and far field Diagram

The "near field" is the area closest to the antenna, also known as the induction field. Field strengths in the near field are different from the far field and can be difficult to predict exact field strengths.

When measuring a transmitter output, the measurements must be made in the "far field". In the far field, the power received per unit area from an isotropic antenna is calculated from the following equation:

Using $\quad P_{r}=\frac{P_{t}}{4 \pi d^{2}}$

Where:

$P_{r}=$ Received power in watt $(s)$.

$P_{t}=$ Transmitter power in watt(s)

$d=$ distance from transmitter in meter $(s)$

$P_{r}=?, P_{t}=20$ watt and $d=100$ meters

$P_{r}=\frac{20}{4 \pi \times(100)^{2}}$

$P_{r}=\frac{20}{4 \pi \times 1000}$ 
$P_{r}=\frac{20}{40000 \pi}$

$\therefore P_{r}=1.59 \times 10^{-4} \mathrm{w}$

$\therefore 1.59 \times 10^{-4} w$ is the received powerfrom the transmitter.

This equation (2) is also referred to as the inverse square law, since doubling the distance gives a fourfold reduction in signal power. Many radio receivers have a manual which includes a specification sheet.

\section{RESUlts}

The outcome of this research gave rise to an FM transmitter equipment with a robust search and discover capabilities in terms of radio transmission. Figure 5. Shows the picture of the device.

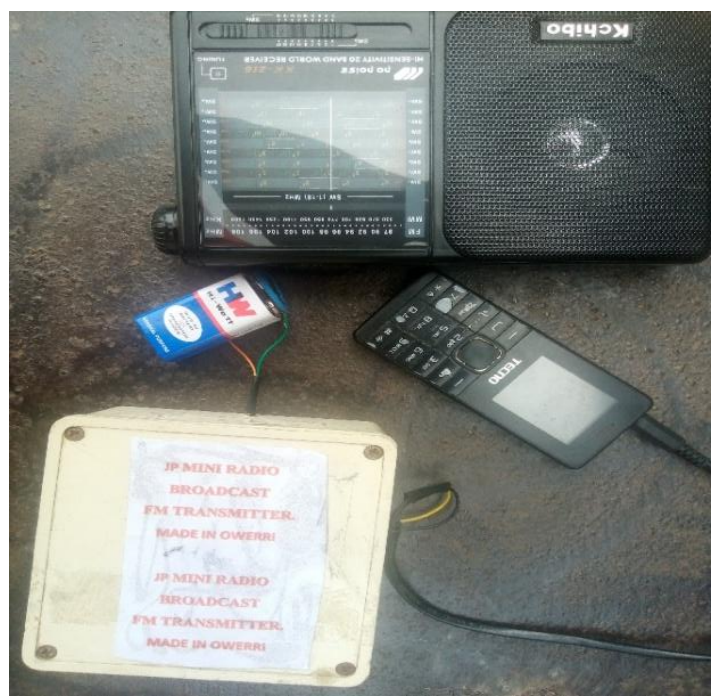

Figure5. Designed and Constructed JP Mini Radio Broadcast FM Transmitter.

In order to assess the functionality of the device, an evaluation test was carried out on the device inside a laboratory.

During the experimental procedure the following test was carried out on the transmitter components using a digital multi-meter.
i. Polarity test
ii. Frequency test
iii. Inductance test

3.1. Polarity test:At every stage of mounting the components especially the ones that have polarity, there comes a need to make use of the digital multi-meter.

3.2. Frequency test:In this experiment the standard frequency test was carried out using a digital multi-meter to note at which frequency the transmitter frequency varies.

3.3. Inductance test:Inductance or mutual inductance refers to when an electrical circuit develops voltage as a result of a change in another circuit. In other form inductance is a ratio of voltage to current and it's measured in a unit called Henry, defined as 1volt-second per ampere.

\section{CONCLUSion}

The test result of this research work revealed the successful achievement of the primary objective; the design, construction and testing of JP Mini Radio Broadcast Transmitter and Audio Console Using Frequency Modulation (FM) With Power Rating of 20 Watt of appreciable range operating on 9v power supply. Because of the impressive good result, obtained from the usability test, the FM transmitter is now ready for either instructional or entrepreneur purposes. The successful completion of this research work has indicated that practical Frequency Modulation (FM) transmitter requiring low power input can be designed and constructed. 


\section{REFERENCES}

[1] Anderson J.B, Rappaport T.S, and Yoshida S. (1994). Propagation Measurements and Models for WirelessCommunication Channels. "IEE', Communication Magazine, UK

[2] Audio-Technical (2016). Radio Frequency Signals Journal, pg. 254

[3] Bacchius C (2005). Antenna Theory Design and Operation. Macmillan Publishing Company, New York third edition.

[4] Chen T. (2002). Radio Frequency Transmission System Journal, pg. 245

[5] Edward R and Durkin J (1969) Computer Prediction of Service Area for VHF mobile Radio Networks, " proceeding of the IEE Canada, vol 116, no. 9, pg. 1493-1500.

[6] Farlex, (2014). Radio. Retrieved from:www.thefreedictionary.com/radio.

[7] George H.O. (1970) Electronics International Edition Heineniemi; Professional Publishing Ltd London.

[8] Jerry C.W (1991). Radio Frequency Transmission System Journal Canada, pg. 235.

[9] JmephMoraski, K4stJM and Charles Spie, W4API (1969) “A Frequency Test for 88-108MHz. "horn Radio, Publisher, Germany, pg. 40

[10] JP.C. Mbagwu, F.M.Ezike and J.O.Ozuomba (2020). International Journal of Scientific \& Engineering Research vol 11, issue 1 Publisher India pg. 536 and 538.

[11] Kennedy and Davis (2001). Electronics Communication Systems. Fourth Edition Publisher U.K pg. 125.

[12] Land Mobile Service (1968). VHF and UHF, "Review of Electrical Communications Laboratory, vol. 16, no. 9 \& 10, pp. 2935-2971, McGraw-Hill Publishers, New York $4^{\text {th }}$ ed. Pg. 216.

[13] Mouser. M Electronics (2016). Instructables Journals Soldering U.S.A pg. 99-100.

[14] Okumura T.S (1968). Radio Spectrum Journals pg. 123-134.

[15] Ogbuanya, T.C, Abul, S., Bakare, J., (2017). The Design and Construction of a Frequency Modulated (FM) Transmitter with output capacity of 10 Watts and Range of about $4 \mathrm{~km}$, International Journal of Applied Engineering Research, 12(18): pp.7516-7523

[16] Peter Baxandall (1790). Audio Power Amplifier, Wireless Wordless Magazine U.S.A pg. 88-97.

[17] Seidel S.Y and Rappaport T.S (1992) 108MHz Path Loss Prediction Models for Indoor.

[18] Verhoeven (2003). Definition; Audio Frequency Amplifier Wikipedia What Is Radio Wave2016.

Citation: JP.C. Mbagwu, et.al., (2020). "Design, Construction and Testing of JP Mini Radio Broadcast Transmitter and Audio Console”.", International Journal of Innovative Research in Electronics and Communications, 7(2), pp. 12-19. DOI: http://dx.doi.org/10.20431/2349-4050.0702003

Copyright: (C) 2020Authors. This is an open-access article distributed under the terms of the Creative Commons Attribution License, which permits unrestricted use, distribution, and reproduction in any medium, provided the original author and source are credited. 